\title{
BMJ Global Health Achieving flexible competence: bridging the investment dichotomy between infectious diseases and cancer
}

\author{
C Norman Coleman (D) , ${ }^{1}$ Monique K Mansoura, ${ }^{2}$ Maria Julia Marinissen, ${ }^{3}$ \\ Surbhi Grover, ${ }^{2,4}$ Manjit Dosanjh (1) ,,5 Harmar D Brereton, ${ }^{2}$ Lawrence Roth, ${ }^{2}$ \\ Eugenia Wendling, ${ }^{2}$ David A Pistenmaa, ${ }^{2}$ Donna M O'Brien ${ }^{2}$
}

\begin{abstract}
To cite: Coleman $\mathrm{CN}$, Mansoura MK, Marinissen MJ, et al. Achieving flexible competence: bridging the investment dichotomy between infectious diseases and cancer. BMJ Global Health 2020;5:e003252. doi:10.1136/ bmjgh-2020-003252
\end{abstract}

Handling editor Seye Abimbola

Received 25 June 2020 Revised 7 October 2020 Accepted 9 October 2020

Check for updates

(C) Author(s) (or their employer(s)) 2020. Re-use permitted under CC BY-NC. No commercial re-use. See rights and permissions. Published by BMJ.

${ }^{1}$ International Cancer Expert Corps (Approved outside activity from $\mathrm{NCl}$ ), Washington, DC, USA ${ }^{2}$ International Cancer Expert Corps, Washington, DC, USA ${ }^{3}$ Health Attache United States Embassy Mexico, Washington DC, USA

${ }^{4}$ Radiation Oncology, University of Pennsylvania Perelman School of Medicine, Philadelphia, Pennsylvania, USA ${ }^{5}$ University of Oxford, Oxford, UK

Correspondence to Dr C Norman Coleman; ccoleman@mail.nih.gov; norm. coleman@iceccancer.org

\section{ABSTRACT}

Today's global health challenges in underserved communities include the growing burden of cancer and other non-communicable diseases (NCDs); infectious diseases (IDs) with epidemic and pandemic potential such as COVID-19; and health effects from catastrophic 'all hazards' disasters including natural, industrial or terrorist incidents. Healthcare disparities in low-income and middle-income countries and in some rural areas in developed countries make it a challenge to mitigate these health, socioeconomic and political consequences on our globalised society. As with IDs, cancer requires rapid intervention and its effective medical management and prevention encompasses the other major NCDs. Furthermore, the technology and clinical capability for cancer care enables management of NCDs and IDs. Global health initiatives that call for action to address IDs and cancer often focus on each problem separately, or consider cancer care only a downstream investment to primary care, missing opportunities to leverage investments that could support broader capacity-building. From our experience in health disparities, disaster preparedness, government policy and healthcare systems we have initiated an approach we call flex-competence which emphasises a systems approach from the outset of program building that integrates investment among IDs, cancer, NCDs and disaster preparedness to improve overall healthcare for the local community. This approach builds on trusted partnerships, multi-level strategies and a healthcare infrastructure providing surge capacities to more rapidly respond to and manage a wide range of changing public health threats.

\section{INTRODUCTION}

The global health impact of poverty and inequality in healthcare access is readily seen in the vulnerability to infectious diseases (IDs) (eg, dengue, tuberculosis, polio, AIDS, etc), many with severe epidemic and pandemic potential (eg, influenza, haemorrhagic fevers and respiratory viruses). The COVID-19 pandemic demonstrates the speed with which an emerging ID can have an overwhelming global impact. ${ }^{1-4}$ (Also (Centers
Summary box

In low-income and middle-income countries, continued investment is needed to address infectious diseases (IDs) and more is needed for non-communicable diseases (NCDs), which are the leading cause of death.

- The aetiological relationship between IDs and cancer is increasingly common (eg, Human papilloma virus (HPV) and cervical cancer and hepatitis $C$ and liver cancer) with many healthcare service needs in common.

- Catastrophic incidents including natural disasters terrorism and pandemics, such as COVID-19, require sustainable healthcare infrastructure to meet sudden surge capacity.

- Global initiatives that address IDs, NCDs and disaster preparedness separately miss the opportunity to support all-hazards capacity-building.

- Cancer care is an ideal entry point to other NCDs as it requires immediate intervention like IDs and attention to the other NCDs and IDs.

- An approach that provides an integrated health system using the flex-competence model described in this paper will support routine care for NCDs, including cancer while being able to rapidly adapt to changing needs as presented by IDs and other catastrophic incidents.

for Disease Control and Prevention) (WHO) updates.) particularly so in the absence of infrastructure for preparedness, planning and rapid operational response. The immediacy of the COVID-19 pandemic presents a strong mandate to engage in preparedness so that lessons-observed become lessons-learnt, with operational action plans and long-term remedies adopted.

Pandemics, large-scale natural disasters (hurricanes and earthquakes) and chemical, biological and radiological/nuclear threat agents can cause 'no-notice' COVID-sized casualties. Globally, per WHO global burden of disease statistics ${ }^{5}$ by disability adjusted life 
years (DALYs), in 2016 'communicable, maternal, perinatal and nutritional conditions' were $\sim 30 \%$ of the global burden compared with $60 \%$ for non-communicable diseases (NCDs), although the reverse was observed in the African region. Malignant neoplasms represented $\sim 10 \%$ of the global burden, increasing with development status. Possibly because they are generally slower to evolve compared with IDs, NCDs (eg, cardiovascular, oncological, respiratory and metabolic diseases) may evoke a lower sense of urgency. Indeed, the importance of the global burden of NCDs was only recognised by the United Nations in 2011. Ensirink pointed out the skewed global health funding as diseases that cause the highest DALYs did not get 'most of the international largesse'.

IDs have been considered the primary threat for global disease spread due to the ease of travel and human-tohuman transmission. Now, however, because of the globalisation of trade and travel, health issues related to NCDs can also produce an international crisis. For example, more than 244 million people have migrated from their countries of origin ${ }^{7}$ over 50 years and rely on the health systems of the receiving countries for their physical and mental health. Access to healthcare is no longer a local or national issue, for example, the COVID-19 dependency on international global supply chains.

Although a number of excellent global initiatives call for action to address IDs, NCDs and public health threats, they focus on each category individually missing opportunities to leverage investments from the outset that could enhance healthcare capacity through a more comprehensive systems approach. This paper proposes using an integrated approach that builds common core capacities to strengthen healthcare systems with personnel and partnerships to prepare for and respond to routine diseases and public health emergencies. From our experience in research, health disparities, disaster preparedness, academic and private healthcare systems and government policy development, we introduce the term flex-competence to describe a healthcare delivery organisation and culture that uses an integrated, rapidly adaptable approach.

\section{CONTEXT AND JUSTIFICATION FOR FLEX-COMPETENCE}

The essence of flex-competence is in the construction of a multi-purpose healthcare system from the outset with the organisational capacity and expertise to adapt to both the predictable needs such as essential maternal, child, general healthcare and disease prevention, and more complex management of IDs and NCDs, while building in flexibility to rapidly address a surge from a pandemic, natural disaster or terrorist incident. In essence, the ability to rapidly rebalance is built in from the ground up within a centre or region such that as the system matures it has the breadth it needs to serve all the illnesses encountered and the systems and supply chains in place for a sudden and large surge. In that there is already a dire need for cancer, its clinical care encompasses other NCDs, and the technology and clinical capability for cancer care enables management of NCDs and IDs, flex-competence improves overall healthcare of the population, enhances resource sharing and has resources early on to adapt rapidly to a surge need. As described later in the paper, flex-competence includes surge capacity, but it requires management expertise and organisational competency with essential features and metrics. What follows is an overview of current global approaches to IDs, 'all hazards' and NCDs, and building on this background, a reconceptualised approach to healthcare systems development with a flex-competence model for achievement of this as a goal.

\section{BUILDING ON THE GLOBAL APPROACHES TO IDS}

IDs, including lower respiratory infections, diarrhoeal diseases and tuberculosis, are among the 10 leading causes of death worldwide and with AIDS and malaria, are among the 6 main causes of death in Africa. ${ }^{8}$ Organisations leading the global efforts to eliminate AIDS and malaria in low/middle-income countries (LMICs) include: The Global Fund to Fight AIDS, Tuberculosis and Malaria, ${ }^{9}$ created in 2002 as an innovative financing mechanism to raise and disburse programme funding; the US President's Emergency Plan For AIDS Relief ${ }^{10}$; the WHO Global Malaria Programme ${ }^{11}$; the UK Global Challenges Research Fund and the Global Alliance for Vaccines and Immunisation.

The COVID-19 pandemic $^{1-4}$ demonstrates how quickly an ID can become a global economic, social, healthcare and political threat. Other threats over the past 20 years include Severe Acute Respiratory Syndrome, influenza, Middle East Respiratory Syndrome Coronavirus, Zika virus and Ebola. The adverse impact of comorbid illnesses, especially NCDs, on the outcome of patients with COVID-19 demonstrates a very strong relationship between NCDs and IDs. ${ }^{2312}$

Although advances in detection and identification of IDs have improved, ${ }^{1}$ COVID-19 has shown that significant time is required to develop medical countermeasures, especially vaccines. Our flex-competence approach would have in place the preparedness and rapid response measures, including anticipation of potentially scarce resources situations ${ }^{13-15}$ with surge capacity of a 'space, staff, supplies and systems' approach . The Global Health Security Agenda (GHSA), a growing partnership of more than 64 nations, international organisations and non-governmental stakeholders, was launched in 2013 to 'help build countries' capacity to ... create a world ... secure from infectious disease threats and elevate global health security as a ... global priority'. GHSA's multilateral, multi-sectoral approach to strengthen global help lays the groundwork for building flex-competence. 
PREPAREDNESS FOR CONSTANT BACKGROUND OF 'ALLHAZARDS' THREATS

Always present is the potential for natural disasters and intentional or accidental threats, with public health and medical consequences. Examples include toxic chemicals and radioactive materials attacks in Asia and Europe, ${ }^{16}$ the intentional anthrax release in the USA in 2001, and the Fukushima Nuclear Power Plant crisis in 2011. To address such threats, the G7 countries, Mexico and the European Commission, with WHO guidance, launched the Global Health Security Initiative in 2001 to enhance preparedness and response policies and protocols, share best practices and coordinate response efforts ${ }^{17}$ in an approach consistent with the underlying principles of our flex-competence model.

In 2005, the WHO and 194 countries agreed to implement the revised International Health Regulations (IHR) with capacity building, processes and investments that became a binding instrument of international law in $2007 .^{18}$ As part of the IHR monitoring and evaluation framework, WHO established the Joint External Evaluation (JEE) tool, through which countries agree to a selfassessment and external evaluation of their capacities, policies and protocols to prevent, detect and respond to public health emergencies of international concern. Since its launch in 2016, more than 100 countries have undergone a JEE and agreed to develop national action plans to address preparedness gaps. The amount spent on threat preparation is not available, however extensive effort was invested by the European Union ${ }^{19}$ and the US government's Office of the Assistant Secretary for Preparedness and Response. ${ }^{20}$

\section{GLOBAL APPROACHES TO ADDRESS THE RISING HEALTH THREAT OF CANCER AND THE OTHER NCDS}

The surge in NCDs is predictable and well-documented, particularly in LMICs. ${ }^{7}$ They are collectively responsible for $\sim 70 \%$ of all deaths worldwide driven primarily by tobacco use, physical inactivity, the harmful use of alcohol and unhealthy diets. In that NCDs will cause a cumulative loss of economic output of $\$ 47$ trillion between 2011 and $2030,{ }^{21}$ it is important that addressing the inexorable rise ${ }^{22}$ of NCDs is included among the UN's Sustainable Development Goal \#3 Good Health and Well-being (bullets \#4, 12, 13) and \#10 Reduced Inequalities (bullet \#10). The 2013-2020 WHO Global Action Plan for the Prevention and Control of NCDs includes a local roadmap for global action that 'will attain nine voluntary global targets, including that of a $25 \%$ relative reduction in premature mortality from NCDs by 2025 (The plan has a global monitoring framework by which governments are urged to (i) set national NCD targets 2025 based on national circumstances; (ii) develop multisectoral national NCD plans to reduce exposure to risk factors and enable health systems to respond in order to reach these national targets in 2025 and (iii) measure results.)'. ${ }^{23}$ Furthermore, the WHO Director General convened an independent, high-level commission on $\mathrm{NCDs}^{24}$ to advise countries how to accelerate progress and The World Economic Forum is exploring how public-private partnerships can do the same. ${ }^{25}$

With the growing burden of cancer becoming apparent, in 2006, the WHO launched a cancer control strategy ${ }^{26}$ which created several advisory committees and working groups that produced publications and guidelines to help countries develop national cancer control programmes that would expand healthcare infrastructure. While efforts to establish such programmes have been undertaken by the International Atomic Energy Agency, the Union for International Cancer Control and several oncology professional societies, they have not been as successful as those for IDs. Lessons learnt from successful actions against IDs certainly can be better applied and integrated with efforts to address cancer and NCDs.

\section{INTER-RELATIONSHIP OF IDS AND CANCER}

The convergence of managing IDs and NCDs is further emphasised in a recent National Academy of Sciences workshop. ${ }^{27}$ Among examples of similar aetiologies and management strategies are the: (i) infectious aetiology of cancer ${ }^{28-31}$ such that vaccinations can prevent and antibiotics can treat infections that cause cancer, for example, viral hepatitis (liver cancer), human papilloma virus infection (cervix and head and neck cancers), and Helicobacter pylori infection (stomach cancer); (ii) environment with air pollution creating disabling respiratory diseases and lung cancer); (iii) diet and the link between metabolic diseases and cancer, for example, obesity and liver cancer and (iv) inflammation, a common mechanism for cardiovascular disease, cancer aetiology and cancer progression. Mutual ID/NCD management allows leveraging of investment, including a cost-effective common infrastructure. Figure 1 illustrates the common healthcare system components for addressing IDs and NCDs. Notably cancer and IDs, require a rapid response.

\section{FLEX-COMPETENCE}

Although the incidence of NCDs is at least as great as that of IDs in LMICs, the latter are given greater investment. Because of the commonality of healthcare resources, including diagnostics, imaging and expertise, flex-competence is an optimal solution. As conditions change, resource utilisation can shift to meet the needs as shown in figure 2 .

\section{ESSENTIAL FEATURES OF A FLEX-COMPETENCE SYSTEMS SOLUTION}

In order to achieve a flex-competence systems solution, metrics are needed with steps detailed in table 1 . 
A Integrated Healthcare System with Flex-competence

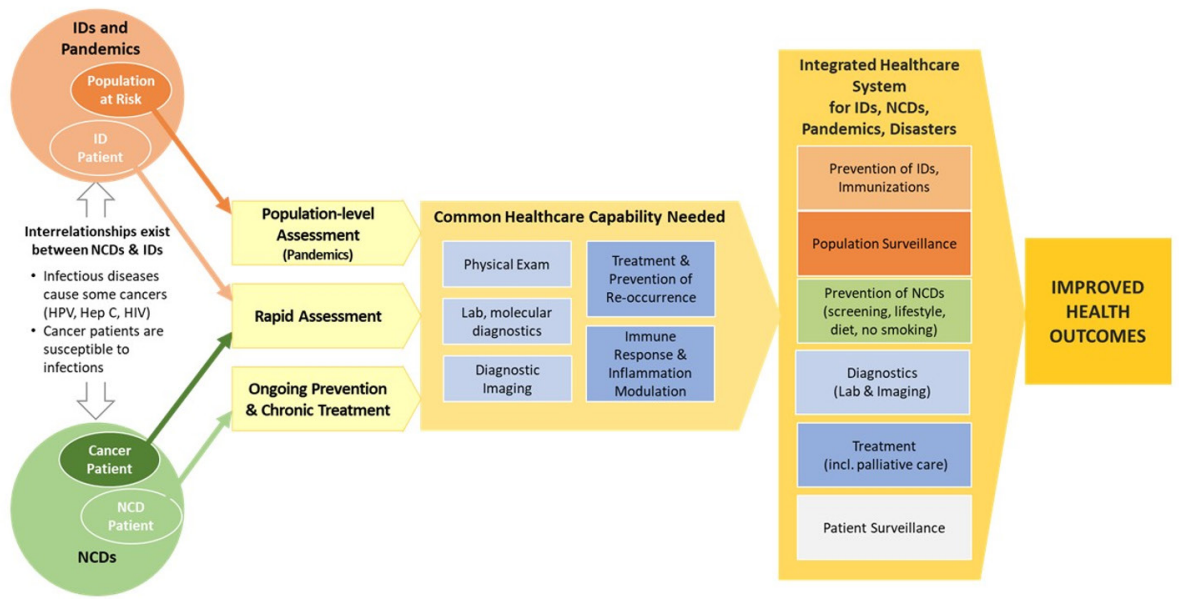

Figure 1 Approaches to infectious diseases (IDs) and non-communicable diseases (NCDs), including aetiology, are similar. Both cancer and IDs are acute illnesses in need of prompt intervention. Similar urgency may be required for other NCDs. The necessary common healthcare capacity and capability are essential parts of an integrated healthcare system. HPV, Human papilloma virus.

\section{Building capacity}

Building capacity for an integrated healthcare system can be accomplished with primary healthcare supplemented by closely linked phased-in specialty expertise with the associated programme development for prevention, screening, treatment and chronic disease management. Phasing-in from the outset avoids the problem caused by sequential approaches in which the steps beyond providing the vital primary, and maternal and child care may never be reached or are delayed for decades. In order to avoid duplication or gaps, the public sector, usually a Health Ministry' must have a leadership role in these efforts.

For cancer treatment there is a global shortage of over 5000 linear accelerators (LINACs) and trained personnel

\section{Flex-competence - Healthcare System's Adaptability to Changing Needs}
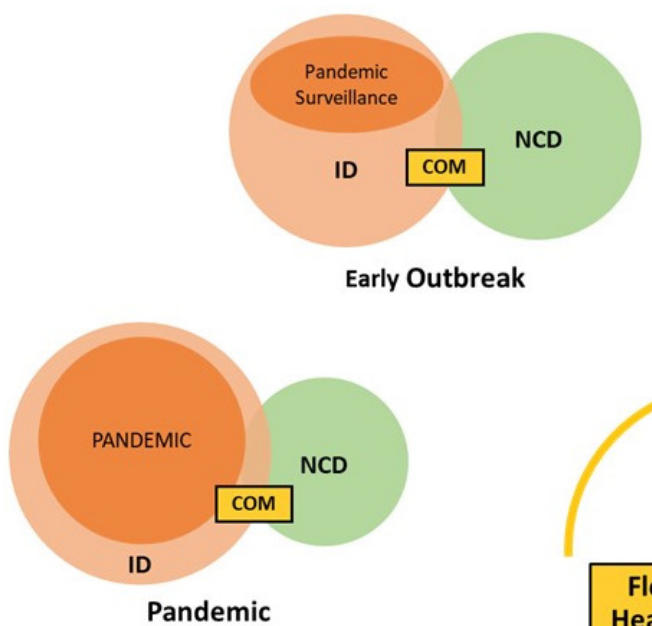

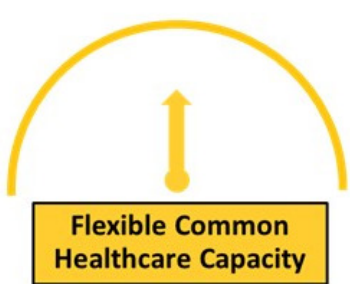

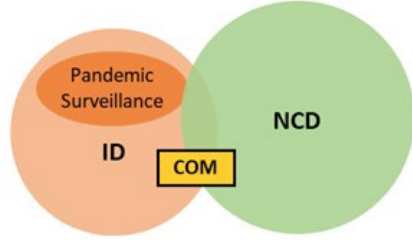

Typical

Figure 2 Four conceptual situations are illustrated. The 'typical setting' in low-income and middle-income countries at top right shows a preponderance of effort toward non-communicable diseases (NCDs). A 'well-vaccinated community', bottom right, devotes more resources to the rising incidence of NCDs. Based on syndromic surveillance and/or the appearance of a new virus on molecular surveillance, the 'early outbreak' (top left) focuses attention and resources toward infectious diseases (IDs). Pandemic surveillance is a component of routine ID care. During an imminent or actual pandemic (bottom left), the healthcare facility serves as a place to assemble ID expertise and supplies on very short notice, rather than requiring many days to weeks to set up a point of distribution. As noted during the COVID-19 response, NCDs may get worse under the stress of a pandemic so NCD care must continue, although at a somewhat reduced level. An essential feature of flex-competence is shown in figure where common (COM) resources are used for all situations with flexible common healthcare capacity, capability and management based on changing priorities. Key: The relative size of the circles represents the amount of effort required during the specific operational focus conditions. COM indicates common resources for all settings, including diagnostic imaging, laboratories, lelemedicine and others. 
Table 1 Essential features for a flex-competence systems solution

\begin{tabular}{|c|c|}
\hline Feature & Metrics \\
\hline Capacity and capability & $\begin{array}{l}\text { Expanded facilities for routine care and primary care, and cancer care, followed by other specialty } \\
\text { care. } \\
\text { Programme development (eg, prevention, treatment). } \\
\text { Expanded cancer expertise. } \\
\text { Meeting global quality standards such as National Comprehensive Cancer Network global cancer } \\
\text { guidelines. }\end{array}$ \\
\hline $\begin{array}{l}\text { Multi-level planning and } \\
\text { management }\end{array}$ & $\begin{array}{l}\text { Multi-level planning as evidenced by a formal planning strategy that includes country, region and } \\
\text { local elements driven by the public sector or health ministry. } \\
\text { Regional planning and regular meetings, most often led by the pubic sector or health ministry, } \\
\text { with processes and communication strategies to support rapid decision-making for changes in } \\
\text { resource deployment and focus, with a trigger for when to access more global resources. } \\
\text { Management structure and ongoing communication systems to support a coordinated plan for } \\
\text { adaptation of plans and implementation. }\end{array}$ \\
\hline $\begin{array}{l}\text { Management and staff } \\
\text { education (for healthcare } \\
\text { system competence to be } \\
\text { adaptable and flexible) }\end{array}$ & $\begin{array}{l}\text { Rapid ability to change systems and focus as evidenced by planning and education and disaster } \\
\text { planning exercises. } \\
\text { A staff training/cross-training plan with specific positions targeted and required education } \\
\text { including interactive educational programmes to assure competency at the top, middle and } \\
\text { frontline staff level. } \\
\text { Ready online access to educational resources for meeting unanticipated and urgent needs (eg, } \\
\text { Radiation Emergency Medical Management). }\end{array}$ \\
\hline Patient engagement & $\begin{array}{l}\text { Planning should include patients and their families. } \\
\text { Systems for ongoing patient input and engagement to be developed. }\end{array}$ \\
\hline $\begin{array}{l}\text { Public sector coordination of } \\
\text { global resource access }\end{array}$ & $\begin{array}{l}\text { Identification of areas that will require access to global resources as evidenced in preparedness } \\
\text { plans which are to be led and coordinated by the public sector and health ministries. } \\
\text { Implementation of regional governance processes to manage priorities, implementation and } \\
\text { deployment of resources. } \\
\text { Documented readiness assessments to meet standards. } \\
\text { Formalised linkage to supply chain networks. } \\
\text { Access to expertise from resource-rich countries for technical assistance, staff mentorship (eg, } \\
\text { International Cancer Expert Corps cancer care mentoring). } \\
\text { Standardised data reporting. }\end{array}$ \\
\hline
\end{tabular}

to operate them. ${ }^{32}$ Some LMICs have few or no LINACs indicating that the specialty care may be delayed indefinitely. Radiation therapy capacity is an excellent metric for cancer care being the standard of care for over $50 \%$ of cancers. The cost of the LINAC presents a significant barrier that requires innovative solutions and strategies for sustainable funding now being considered. ${ }^{33} 34$

\section{Multi-level planning and management}

Planning for flex-competence must be coordinated at multiple levels to include policy and payment, regional services, organisational programmes, clinical programmes and personnel, patients and their families, and community health and outreach with both public and private sectors included. Integrated healthcare services that can manage IDs, NCDs and other threats such as pandemics are the underpinning of a robust healthcare system. Centres within a geographic region can provide ongoing management of diseases while conducting surveillance for 'hot-spots', 35 and then rapidly change focus to meet an outbreak or other disaster. This allows care to be organised across a region, enabling routine patients to be treated elsewhere, as needed. Such a multi-level regional management structure for the coordination of and cooperation for resources and personnel will ensure a match between capacity and needs.

\section{Education}

The key factor of adaptability is provided by education and skill development in change management and crosstraining for rapid deployment when needed to address changing focus. New educational approaches are needed to train the clinical workforce to meet the demands of an integrated healthcare system. This requires focus on the variety of illnesses to be encountered and the skills and flexibility for diagnosis, treatment, epidemiology and public health. A similar approach applies to administrative, laboratory and ancillary staff. A mentorship model, such as that provided by the International Cancer Expert Corps, offers expertise through mentoring over extended time.

\section{Patient and family engagement}

Understanding the perspective of patients and promoting patient engagement are important as a flex-competent system should include patients and their families in planning and programme evaluation. Systems for collecting 


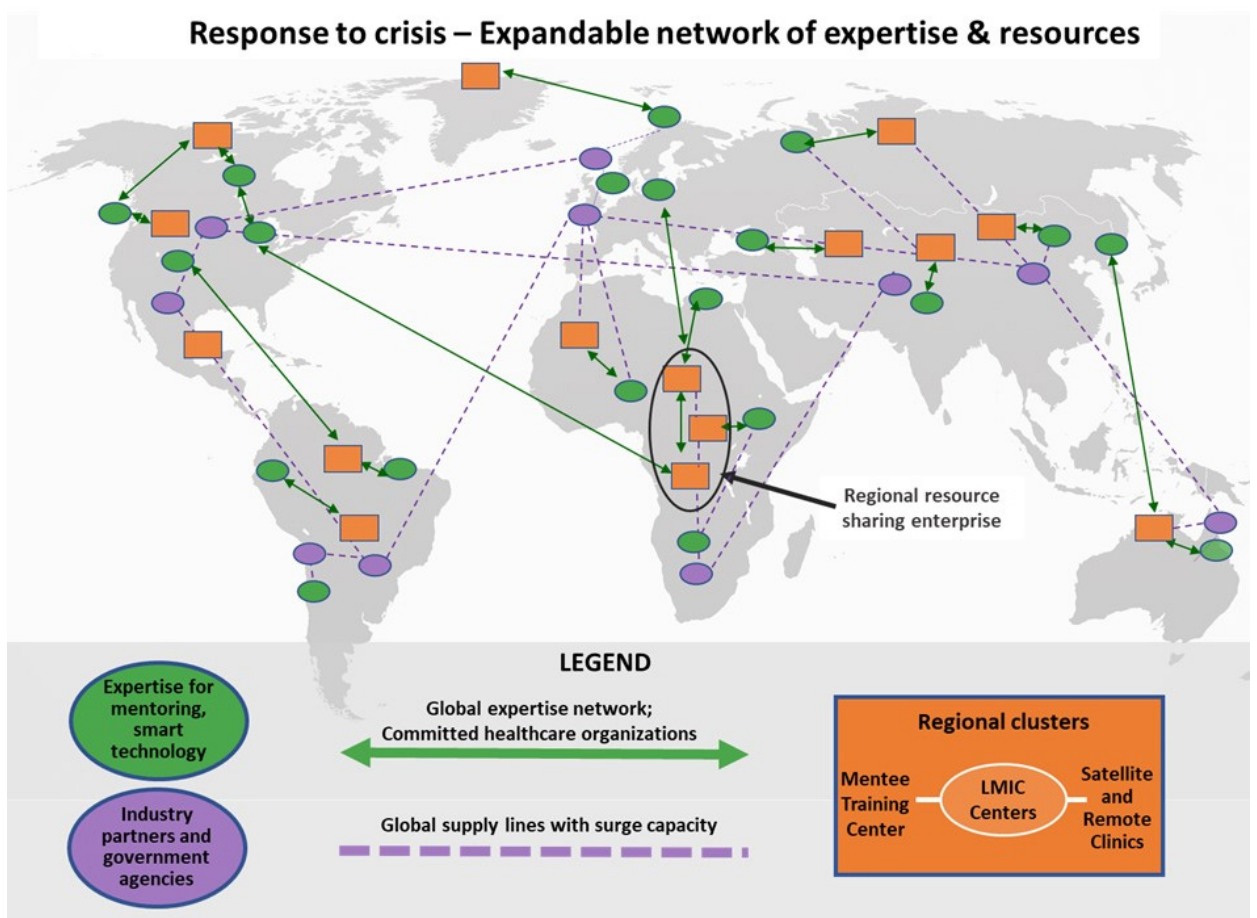

Figure 3 The healthcare system has three major components: (i) centres in low/middle-income countries (LMICs) and geographically remote areas in high-income countries (often indigenous populations) (orange) are composed of regional centres, remote clinics or satellite facilities within local communities; (ii) organisations that provide expert advice and mentorship (green) and (iii) industry and governmental entities that comprise a stable and rapidly expandable supply line (purple). In a surge situation, these components can be coordinated for a rapid response that efficiently distributes and coordinates care across a region (regional resource-sharing enterprise); provides expertise through ongoing training and mentoring (eg, the International Cancer Expert Corps sustainable mentorship model) enhanced by smart technology and remote assistance; and puts a system in place to augment supply lines regionally and globally.

feedback for ongoing assessments from patients should be implemented.

\section{Public sector coordination for access to resources globally}

The public sector and health ministries need to establish a coordinated programme for accessing external resources and supply chain networks so that priorities are set and managed. Figure 3 illustrates that effective healthcare capacity requires a flexible platform to anticipate, detect and respond to changing priorities.

\section{INTEGRATED EXPERIENCE 'ON THE GROUND'}

An example of how one can build flex-competence is found in Botswana, a country of 2.5 million people, $18 \%$ of whom are infected with HIV, ${ }^{36}$ where management of IDs and NCDs are part of the same healthcare system. Botswana developed the first public HIV treatment programme in Africa. Its coverage now exceeds that of even the best-performing high-income countries. ${ }^{37}$ With expanding access to antiretroviral therapy, patients are living longer, resulting in rising rates of NCDs, such as cancer and heart disease. ${ }^{38}$ NCDs are Botswana's second wave of AIDS. Developing a strategy for dealing with them, especially with cancer, is now a major focus of the Ministry of Health that is now developing Botswana's first public radiation oncology centre. This centre features two LINACs, a brachytherapy unit, and investment in a systems model for cancer care that enables prevention, screening, treatment and palliative care. Without the essential radiation therapy capability, treatment for most solid tumours is significantly limited. So, the common need for diagnostic imaging, laboratory and pathology diagnoses and ID expertise could be developed from the outset with the radiation therapy capability integrated within the initial basic health system with flexcompetence.

\section{CONCLUSION}

Our flex-competence approach calls for healthcare system investment integrating care for IDs and NCDs with public sector coordination which is critical for longterm solutions to both disease groups. Primary care is the cornerstone of care delivery but benefits substantially from investment in what is minimally needed for effective cancer care-essential diagnostics, imaging, radiation therapy and expertise accessible locally and through network partners. Preparedness for IDs is key because these threats can progress rapidly and much faster than the lead time for vaccine production and, when needed, novel medical countermeasure development. COVID-19 responses show how losing precious time in deploying personnel and supplies, which often come from other countries, and failure to coordinate the implementation 
of public health measures can have substantial human and economic loss. The problem is that preparedness, response and resilience regarding global health security threats are expensive and can be misunderstood as a waste of money should the threat not materialise in an expected time frame. However, the flex-competence approach will reduce the cost of preparation and enable an effective response to disasters. Furthermore, preparedness for pandemics and other public health disasters can be made affordable with a return-on-investment by jointly addressing both them and the already present global rise in NCDs. ${ }^{39} 40$ Public support and buy-in across national governments is necessary to accommodate the cost and scope of services needed for such a highly coordinated global system. However, the improved health and economic development can be strong incentives. The private-sector can bring its supply chains and global networks to ensure surge capacity while nongovernmental organisations can focus on specific expertise needs that can enhance the capability of the local staff.

There are similarities and differences between flexcompetence and surge capacity. Surge capacity is most often based on an event linked to disaster preparedness. ${ }^{41}$ Flex-competence is the ongoing ability for an organisation and its staff to adapt to changing patient care or public health needs. It draws on the concepts of flexing the health workforce to adapt to changing needs ${ }^{42}{ }^{43}$ and on change management which requires expertise and an organisational culture that continuously and rapidly adapts and innovates with a fully engaged ${ }^{44}$ staff. For developing alliances across regional, national and international organisations the essential characteristics include building trust and investment in a shared infrastructure and public sector engagement. ${ }^{45} 46$ Flexcompetence offers what is needed for comprehensive all-hazards preparedness and response as well as the establishment of resources for preventing, detecting and treating routine IDs and NCDs, and primary care including support of maternal/child programmes, such as those described by the Kaiser Family Foundation. ${ }^{21}$ Organisational and management competency in change management are necessary at multiple levels to adapt and reorder priorities based on changing environmental conditions. ${ }^{47} 48$

COVID-19 has demonstrated starkly that the cost of pre-emptive investment in preparation is necessary and saves lives, dollars, public confidence and disruption of the economy and life. The flex-competence multi-level systems-building approach more effectively responds to changing needs whether from the rise of NCDs the ongoing need to prevent and treat IDs or the need for preparedness for 'all-hazard' threats. Incorporating cancer care capability in the earliest steps of establishing a healthcare system is important, as noted by Harvey Fineberg, 'if we can solve the problems of cancer care, we hold the key to solving healthcare more broadly'. ${ }^{49}$ The flex-competence approach recognises that daunting healthcare challenges in a pandemic require 'readywired' global systems with public sector engagement to promote expertise and strengthen supply lines. The proposed solutions work when there is (i) sustained institutional and health ministry commitment, investment and constancy of purpose ${ }^{50}$; (ii) management with skills to drive organisational cultures and relationships to support the goals and to support regional coordination by the public sector; (iii) trusted relationships; (iv) access to expertise at all levels and (v) recognition for the value of participants' contributions. ${ }^{49}$ That such programmes do not exist now on the scale needed ${ }^{51}$ may be due, in part, to the historical approach of addressing IDs and NCDs as distinct problems. Framing this issue as a systems challenge provides dual-utility investment and rapidity of response that could forestall catastrophe.

Common and terrifying diseases, such as cancer, have no geographic boundaries and do not distinguish among individuals. The human need for care and compassion and the reality of the value of each and every life provide a foundation for collaboration and an incentive and template for immediate and effective action. As noted by John Gardiner, President Lyndon Johnson's Secretary of Health, Education, and Welfare, president of the Carnegie Corporation, and leading contributor to global health, education and social causes, 'What we have before us are some breathtaking opportunities disguised as insoluble problems'.

Acknowledgements Linda Kastleman for editorial assistance and to Alice Saunders for graphic design support.

Contributors All authors contributed to the conceptual development and implementation of the project. They all contributed to the preparation of the manuscript.

Funding The authors have not declared a specific grant for this research from any funding agency in the public, commercial or not-for-profit sectors.

Disclaimer This article reflects the authors' personal opinions regarding globa health disparities and does not represent opinion or policy of the companies (MKM) or federal agencies (CNC, MJM) through which they are employed. The International Cancer Expert Corps (ICEC) is an 'official outside activity' for CNC. MKM, MJM, SG DMO'B, MD, HDB, LR, DAP and CNC are non-reimbursed advisors to the International Cancer Expert Corps, Washington, DC, Geneva Switzerland and Toronto, Canada. EW is ICEC's Chief Operating Officer.

Competing interests None declared.

Patient consent for publication Not required.

Provenance and peer review Not commissioned; externally peer reviewed.

Data availability statement There are no original data in this work.

Open access This is an open access article distributed in accordance with the Creative Commons Attribution Non Commercial (CC BY-NC 4.0) license, which permits others to distribute, remix, adapt, build upon this work non-commercially, and license their derivative works on different terms, provided the original work is properly cited, appropriate credit is given, any changes made indicated, and the use is non-commercial. See: http://creativecommons.org/licenses/by-nc/4.0/.

\section{ORCID iDs}

C Norman Coleman http://orcid.org/0000-0003-3121-1663

Manjit Dosanjh http://orcid.org/0000-0003-1378-349X

\section{REFERENCES}

1 Zhu N, Zhang D, Wang W, et al. A novel coronavirus from patients with pneumonia in China, 2019. N Engl J Med 2020;382:727-33. 
2 Zhou F, Yu T, Du R, et al. Clinical course and risk factors for mortality of adult inpatients with COVID-19 in Wuhan, China: a retrospective cohort study. Lancet 2020;395:1054-62.

3 Guan W-J, Ni Z-Y, Hu Y, et al. Clinical characteristics of coronavirus disease 2019 in China. N Engl J Med 2020;382:1708-20.

4 Munster VJ, Koopmans M, van Doremalen N, et al. A novel coronavirus emerging in China - key questions for impact assessment. N Engl J Med 2020;382:692-4.

5 World Health Organization. Disease burden and mortality estimates. Available: https://www.who.int/healthinfo/global burden disease/ estimates/en/index1.html [Accessed 26 Aug 2020].

6 Enserink M. After the windfall. Science 2014;345:1258-9.

7 Connor P. International migration: key findings from the U.S., Europe and the world. Pew research center website, 2016. Available: https:// www.pewresearch.org/fact-tank/2016/12/15/international-migrationkey-findings-from-the-u-s-europe-and-the-world/ [Accessed 26 Aug 2020].

8 World Health Organization. Top 10 causes of death. Available: https://www.who.int/gho/mortality_burden_disease/causes_death/ top_10/en/ [Accessed 26 Aug 2020].

9 The global fund website. Available: https://www.theglobalfund.org/ en/ [Accessed 26 Aug 2020].

10 U.S. President's Emergency Plan for AIDS Relief (PEPFAR) website. Available: https://www.hiv.gov/federal-response/pepfar-global-aids/ pepfar [Accessed 26 Aug 2020].

11 World Health Organization. Global malaria programme. Available: https://www.who.int/malaria/about_us/en/ [Accessed 26 Aug 2020].

12 Chang TS, Ding Y, Freund MK, et al. Prior diagnoses and medications as risk factors for COVID-19 in a Los Angeles health system. medRxiv 2020.

13 Knebel AR, Sharpe VA, Danis M, et al. Informing the gestalt: an ethical framework for allocating scarce federal public health and medical resources to states during disasters. Disaster Med Public Health Prep 2014;8:79-88.

14 Timbie JW, Ringel JS, Fox DS, et al. Systematic review of strategies to manage and allocate scarce resources during mass casualty events. Ann Emerg Med 2013;61:e101:677-89.

15 Hick JL, Hanfling D, Wynia MK, et al. Duty to plan: health care, crisis standards of care, and novel coronavirus SARS-CoV-2. National Academy of medicine website. Available: https://nam.edu/duty-toplan-health-care-crisis-standards-of-care-and-novel-coronavirussars-cov-2/ [Accessed 5 Mar 2020].

16 Stockholm international peace research Institute. Reassessing CBRN threats in a changing global environment. Available: https:// www.sipri.org/publications/2019/other-publications/reassessingcbrn-threats-changing-global-environment [Accessed 26 Aug 2020].

17 Global health security initiative. Available: http://www.ghsi.ca [Accessed 26 Aug 2020].

18 World Health Organization. International health regulations, 2005 Available: https://www.who.int/ihr/9789241596664/en/ [Accessed 26 Aug 2020].

19 Chatfield SN, for the European Parliament. Member States' Preparedness for CBRN Threats. Available: http://www.europarl. europa.eu/RegData/etudes/STUD/2018/604960/IPOL STU(2018) 604960_EN.pdf [Accessed 26 Aug 2020].

20 Office of the assistant Secretary for preparedness and response U.S. department of health and human services. National health security strategy, 2019-2022, 2020. Available: https://www.phe.gov/ Preparedness/planning/authority/nhss/Documents/NHSS-Strategy508.pdf

21 Kaiser Family Foundation (KFF). The U.S. government and global non-communicable disease efforts. Available: https://www.kff.org/ global-health-policy/fact-sheet/the-u-s-government-and-global-noncommunicable-diseases [Accessed 26 Aug 2020].

22 World Health Organization. Third United nations high-level meeting on NCDS. Available: https://www.who.int/ncds/governance/third-unmeeting/en [Accessed 26 Aug 2020].

23 World Health Organization. Global action plan for the prevention and control of NCDS 2013-2020. Available: https://apps.who.int/iris/ bitstream/handle/10665/94384/9789241506236_eng.pdf;jsessionid= DAF4A8971AF6232125F9FFBF90679DD9?sequence $=1$ [Accessed 26 Aug 2020].

24 World Health Organization. Noncommunicable diseases and their risk factors. Available: https://www.who.int/ncds/governance [Accessed 26 Aug 2020].
25 Jain C. How public private partnerships must evolve to create social impact. Available: https://www.weforum.org/agenda/2019/11/howpublic-private-partnerships-must-evolve-to-create-social-impact [Accessed 26 Aug 2020].

26 World Health Organization. Who cancer control strategy. Available: https://www.who.int/cancer/media/strategy/en [Accessed 26 Aug 2020].

27 Ogawa VA, Shah CM, Negussie Y, et al. The convergence of infectious diseases and noncommunicable diseases: proceedings of a workshop. Washington, DC: The National Academies Press, 2019. https://www.nap.edu/catalog/25535

28 Howley PM. Gordon Wilson Lecture: infectious disease causes of cancer: opportunities for prevention and treatment. Trans Am Clin Climatol Assoc 2015;126:117-32.

29 de Martel C, Georges D, Bray F, et al. Global burden of cancer attributable to infections in 2018: a worldwide incidence analysis. Lancet Glob Health 2020;8:e180-90.

30 Remais JV, Zeng G, Li G, et al. Convergence of non-communicable and infectious diseases in low- and middle-income countries. Int $J$ Epidemiol 2013;42:221-7.

31 Kostova D, Husain MJ, Sugerman D, et al. Synergies between communicable and noncommunicable disease programs to enhance global health security. Emerg Infect Dis 2017;23:S40-6.

32 Atun R, Jaffray DA, Barton MB, et al. Expanding global access to radiotherapy. Lancet Oncol 2015;16:1153-86.

33 Dosanjh M, Aggarwal A, Pistenmaa D, et al. Developing innovative, robust and affordable medical linear accelerators for challenging environments. Clin Oncol 2019;31:352-5.

34 Pistenmaa DA, Dosanjh M, Amaldi U, et al. Changing the global radiation therapy paradigm. Radiother Oncol 2018;128:393-9.

35 Allen T, Murray KA, Zambrana-Torrelio C, et al. Global hotspots and correlates of emerging zoonotic diseases. Nat Commun 2017;8:1124.

36 Republic of Botswana. Botswana AIDS impact survey 2013: statistical report. Available: http://www.statsbots.org.bw/sites/ default/files/publications/BOTSWANA\%20AIDS\%20IMPACT\% 20SURVEY\%20IV\%202013.pdf [Accessed 18 Aug 2020].

37 Gaolathe T, Wirth KE, Holme MP, et al. Botswana's progress toward achieving the 2020 UNAIDS 90-90-90 antiretroviral therapy and virological suppression goals: a population-based survey. Lancet HIV 2016;3:e221-30.

38 Dryden-Peterson S, Medhin $\mathrm{H}$, Kebabonye-Pusoentsi M, et al. Cancer incidence following expansion of HIV treatment in Botswana. PLoS One 2015;10:e0135602.

39 Leatherman S, Berwick D, lles D, et al. The business case for quality: case studies and an analysis. Health Aff 2003;22:17-30.

40 Nelson C, Lurie N, Wasserman J. Assessing public health emergency preparedness: concepts, tools, and challenges. Annu Rev Public Health 2007;28:1-18.

41 Watson SK, Rudge JW, Coker R. Health systems' "surge capacity": state of the art and priorities for future research. Milbank $Q$ 2013;91:78-122.

42 Nancarrow SA. Six principles to enhance health workforce flexibility. Hum Resour Health 2015;13:9.

43 Britnell M. Human: solving the global workforce crisis in healthcare. Oxford University Press, 2019

44 Katz D, Kahn RL. The social psychology of organizations. New York: Wiley, 1978.

45 Kaluzny A, Zuckerman H, Ricketts T. Partners for the dance: strategic alliances in health care. Ann Arbor, MI: Health Administration Press, (1995) Reprinted Beard Books, Washington, D.C, 2002.

46 Mazzucato M. The Entrepreneurial state: debunking private vs public sector myths. New York: Penguin, 2013.

47 Mintzberg H. Managers Not MBA's: A Hard Look at the Soft Side of Management and Management Development. Oakland, CA: BerrenKoehler, 2004.

48 Kotter J. Leading change. Boston: Harvard Business Review Press, 1996.

49 Deming WE. The new economics for industry, government and education. 2nd ed. Cambridge, MA: MIT Press, 1994.

50 Fineberg H. Delivering affordable cancer care in the 21st century: workshop summary. Institute of medicine of the National academies. Washington, D.C: The National Academies Press, 2013.

51 Coleman CN, Wendling EN, Pistenmaa DA. A broad impact for global oncology. JAMA Oncol 2019;5:1397-8. 